Canadian University Music Review

Canadian University Music Review

Revue de musique des universités canadiennes

\title{
On Tonality and Tonal Form in the Serial Music of Arnold Schoenberg
}

John MacKay

Numéro 8, 1987

URI : https://id.erudit.org/iderudit/1014934ar

DOI : https://doi.org/10.7202/1014934ar

Aller au sommaire du numéro

Éditeur(s)

Canadian University Music Society / Société de musique des universités canadiennes

ISSN

0710-0353 (imprimé)

2291-2436 (numérique)

Découvrir la revue

Citer cet article

MacKay, J. (1987). On Tonality and Tonal Form in the Serial Music of Arnold

Schoenberg. Canadian University Music Review / Revue de musique des

universités canadiennes, (8), 62-77. https://doi.org/10.7202/1014934ar

All Rights Reserved (C Canadian University Music Society / Société de musique des universités canadiennes, 1986
Ce document est protégé par la loi sur le droit d'auteur. L'utilisation des services d'Érudit (y compris la reproduction) est assujettie à sa politique d'utilisation que vous pouvez consulter en ligne.

https://apropos.erudit.org/fr/usagers/politique-dutilisation/ 


\section{ON TONALITY AND TONAL FORM IN THE SERIAL MUSIC OF ARNOLD SCHOENBERG}

\section{John MacKay}

Over the course of his theoretical writings, Schoenberg issued many poignant judgments on the "tonality" of his serial and pre-serial music, but not without apparent inconsistencies and contradictions. One finds, for example, comments that the cyclic nature of serial procedures assured that no one tone would predominate over the others (1975: 219-220 and 246) or that the structural functions of chords in serial music do not derive from harmonic principles (1954: 194) and that complete recourse should be made to the structure of the row as the premise of tonal coherence (1975: 246-7). On the other hand, one finds a complete abhorrence of the term "atonal" when applied to any of his music, a strong belief in the eventual discovery of the "tonality" of his serial music (since "tonality" for Schoenberg was more an issue of aural understanding than of particular harmonic materials and idioms) and a conviction that critical/analytical judgments of this music should be made by listening rather than via observations of its technical peculiarities (1975: 283-4). Schoenberg's most clearly focussed discussion of issues of "tonality" and form is to be found in an article entitled "Problems of Harmony" where he associates organizational and functional impressions of "tonality" with particular harmonic principles, factors of cadence, form and modulation, and harmonic/motivic consistency. The very general but essential synthesis at which Schoenberg arrives is that

One thing is certain: all chords that in any way may turn to a key, no matter how dissonant they may be, fall within the domain of the old harmony and do not disturb tonality. It might be further said that tonality does not depend upon the number of dissonances used or their eccentric effect, but rather: 1) on whether these chords may be referred 
to a key; or 2) whether these relations are convincingly enough worked out.

It is striking to see Schoenberg's reference to the common practice concept of a "key" in this generalized explanation of tonal comprehensibility. This is founded to a considerable extent on an appeal to the overtone series (1975: 271) as the natural basis for harmonic and melodic coherence. The tones or chords closest together in the overtone series form the most natural harmonic groupings or successions as in triadic structurings and progressions of the diatonic keys. Conversely, those which are farther apart in the overtone series form more forced or artificial associations which may nevertheless be involved in convincing expressions of tonal logic (as in chromatically altered scale degrees or the more complex pre-serial and serial tonal structurings).

Although the second part of the statement is quite vague, Schoenberg has, elsewhere in the essay, revealed what he views to be relations which are "convincingly" worked out. Perhaps foremost among these is the sense of cadence and cadential emphasis relative to different tonal centres within the phrase and formal structure of a work (see 1975: 278) This will be termed "tonal form" here. Schoenberg terms this the "art means" of a piece (1975: 275) which is necessary for the perception of a particular tonal logic.

Although it is never specifically mentioned, one must also assume that melodic or harmonic successions can be "convincingly worked out" by clearly directed voice-leading which creates a sense of motion and goal regardless of the nature of harmonic and melodic materials and regardless of whether there is a cadential or repetitive centering of a particular tone or sonority (1975: 248). This is most clearly illustrated in the following two chorale-style examples from "Problems of Harmony" (1975: 229 and 230). A series of consonant but non-key-related sonorities (in the first example which is Schoenberg's example 5 from "Problems of Harmony") is compared with a series of more dissonant chords which are nevertheless clearly organized with directed motions to stable sonorities on A and D. Schoenberg defers judgment on which of these is more "tonal", but it is interesting to note, in each case, the 
very tightly organized control of linear direction and function in all voices of the texture.

Beispiel,

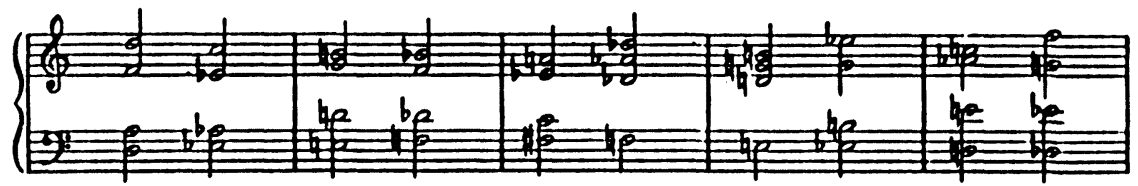

Beispiel 6

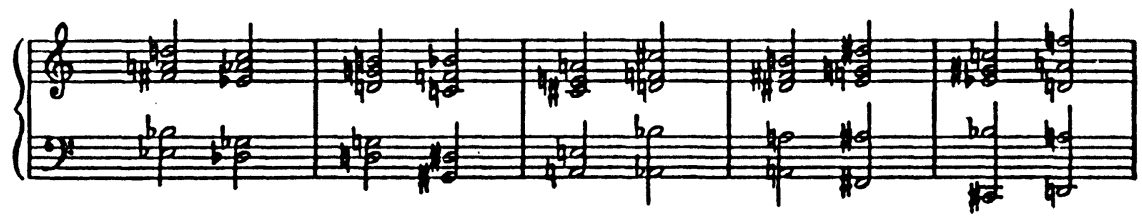

Figure 1. : From "Problems of Harmony" in Style and Idea (1975), pp. 229-230

Finally, in a most revealing speculation, Schoenberg claims that the integrity of motivic design and function is, at least for him personally, of greater interest than the consistent and "grammatical" organization of the harmonic texture (See 1975: 279). Although he admits the central role of harmonic consistency and function in the perception of a tonality, he attaches a higher value to motivic development in the "intelligibility" and significance of a work. Moreover, Schoenberg believes that the tonal implications of complex harmonic materials which defy simplistic triadic organization (i.e. 5- or more-note chords as typically found in his serially music in his example 6 above) have yet to be fully defined. They could therefore be explored compositionally for the 
possibilities that they might yield in terms of new forms of harmonic order.

These aesthetic/compositional tenets, greatly clarify Schoenberg's use of the twelve-tone method and its relation to his expressions of tonality and form. It has been generally recognized that motivic coherence is closely associated with Schoenberg's original conception and use of the row. Traditional formal function and serial structure are, in fact, very closely inter-related in Schoenberg's neo-classical works where specific formal and motivic functions are articulated by the serial structure. Despite the relatively few studies of this aspect of Schoenberg's serial music, ${ }^{1}$ his theories of thematic function and process are very well documented. ${ }^{2} \mathrm{He}$ conceptualizes three categories of thematic structure. To recall briefly these concepts, simple themes are constructed following the three basic models. The period consists of the typical parallel antecedant and consequent phrases ending respectively with a half and full close in the normal textbook sense of these terms. The sentence consists of an opening motivic model which is immediately repeated either exactly or with slight variation, followed by (usually two) shorter phrases which function as further developments called "reductions". ${ }^{3}$

1 The reader is referred to a dissertation by Wil Ogdon (treating works of Schoenberg, Webern, Krenek, and Leibowitz) and also to an unpublished work by Rene Leibowitz entitled "A Treatise on Twelve Tone Composition" which examines the disposition of row statements in relation to the traditional models of form and phrase structure with which Schoenberg worked. The best known essay on the relation of series structure to form is Leibowitz' "Qu'est-ce que c'est que la Musique de Douze Sons?" which deals in detail with the Concerto Op. 24 of Webern.

2 All definitions in the following discussion are taken from Schoenberg's text book Fundamentals of Musical Composition edited by Gerald Strang and Leonard Stein (Boston: Faber, 1967).

3 These shorter phrases need not be actual fragments of the motivic model and can also be free material or even further full repetitions of the model itself which lead directly to a cadence. Examples and explanations of Schoenberg's idioms of thematic structure and process are to be found in chapter eleven of Structural Functions of Harmony, pp. 114-191. The most 
The Lied or short ternary structure consists of an initial period structure followed by a short contrasting phrase (usually on the dominant in the common practice idioms) which is succeeded by a return of the consequent of the opening period which closes off the structure.

Schoenberg's notions of thematic process encompass a wide variety of terms including "liquidation" - the gradual fragmentation of the initial thematic structure, "neutralization" - the eventual dissolution of thematic ideas into commonplace or "neutral" figuration, and "saturation" - the repetition of an idea so as to exhaust its interest and create the anticipation of the entrance of a new idea. Other aspects of Schoenberg's terminology are fairly standard and self-explanatory in the parlance of formal analysis (episode, bridge, transition, secondary idea etc.).

The articulation of tonal logic which was available in Schoenberg's common practice examples was also available in the neoclassical serial idiom (i.e. the serial works after the Quintet Op. 26 which involve typical sonata forms, thematic structurings and developments). Although they will not have the obvious common practice alternation of tonic and dominant, the thematic and cadential organization of the serial works often articulates very clear logics of emphasis, departure/alternation, and return in relation to specific tones or series aggregates. This can be demonstrated by looking at a couple of Schoenberg's serial themes, not simply in terms of phrase structure and serial structure (which has already been done elsewhere) ${ }^{4}$ but in terms of their cadential emphasis and directed motions to specific central tones. The opening theme of the Klavierstücke Op. 33b (see Figure 2a) falls fairly clearly into a ternary design which is interrupted momentarily by a short scherzando motive. The outer phrases of the ABA structure contain motivic couplets which, on the other hand,

often-cited example of the sentence structure is the opening eight-measure theme of the first movement of the Beethoven Sonata, Op2/1. A typical short ternary structure is to be found in the Rondo theme of the Sonata Op. $2 / 2$.

4 See footnote 1 . 
(a) Op. 33b, measures 1-15;

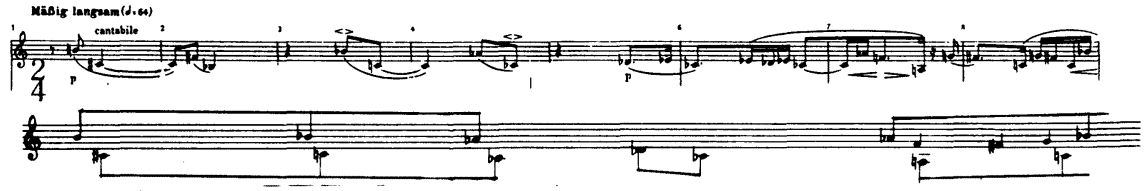

Poco rit.. ${ }_{10}^{\circ}{ }^{\circ}$-poco scherzando

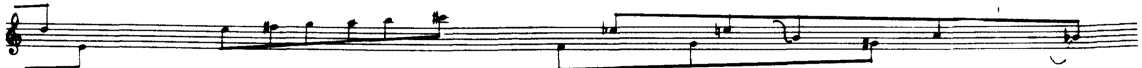

(b) Op. 31, measures 34-57

Molto moderato $(d=88)$
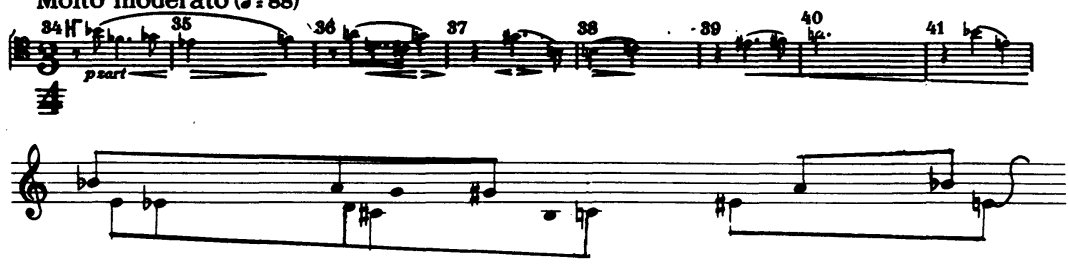

Vel
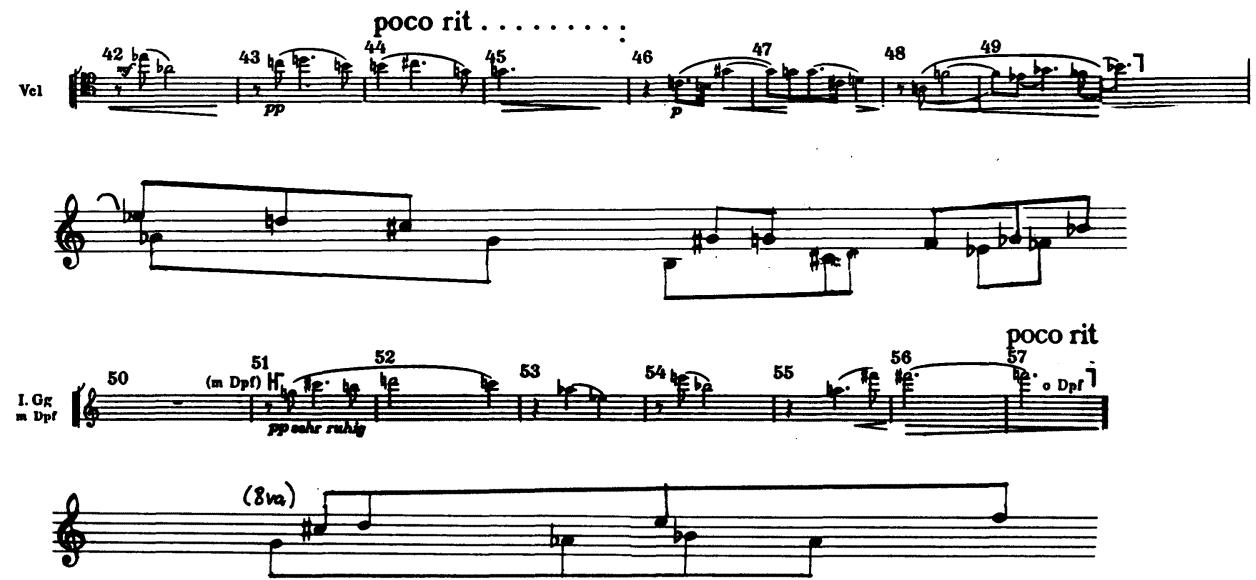

2. - registral displacement of melodic tones

- principal tonal structural motions

Figure 2: 
suggest the type of tonal symmetry which is usually found in period structure. The melodic centering in the theme places considerable emphasis on B natural. It is this pitch which begins and closes the opening motivic couplets and a B centering is defined by the prominence of upper and lower neighbours on B-flat and C-natural in measures two and three. (See the accompanying voice-leading reductions beneath each example.) The B-centering is even more clearly stated (with strong diatonic implications) in the contrasting idea which is perhaps a fuller realization of the B-centering in the opening measures. After the upper register excursion (m. 8-14) the emphasis on B returns but the final cadence is left open, ending on the lower neighbour B-flat.

The structure of the theme of the Variations for Orchestra Op. 31 (see Figure $2 b$ ) is also in a ternary design and again articulates a short motivic fragment. However, it is a series of carefully directed chromatic voice-leadings which unifies the theme, witholding the principal melodic center until the closing cadence. The three successive motivic statements of the opening phrase descend to the first cadence on $\mathrm{C}$ in measure 38. The following parallel phrase appears to pursue the upper linear component of this line which had left off on G-sharp in measure 37. Passing through A-natural and A-flat, it settles on the G-natural (in measure 45), retracing the linear descent of the upper melodic component seen in measures 35 to 39 . The central section is simply a retrograde of the opening measures except for the displacement of the A-natural which clarifies the linear descent through G-sharp, G-natural, and F. The close of the central section on the tritone F-flat/B-flat is significant since these tones are rigorously targeted as the goals of linear chromatic ascent in the closing phrase (lower component G/A-flat/B-flat and the upper component C-sharp/D/E) culminating in the resolution of the tritone (on $\mathrm{F}$ and $\mathrm{A}$ ) as the closing linear goal of the theme..$^{5}$

5 The reader is very strongly urged to consult Schoenberg's radio interview transcribed in The Score and IMA Magazine, 33, July 1960 where he actually provides a densely modulatory but triadic harmonization of the serial melody of the Orchestral Variations Op. 31, and comments on the centering 


\section{The Minuet of the Suite Op. 25}

It is not surprising to see in the evolution of Schoenberg's musical language a movement toward the integrated formal expressions of neoclassicism which accompanied the integrative systematization of pitch organization of the serial method. The Minuet of the Suite Op. 25 is a perfect example of this, admitting only slight phrasal extensions and typical Schoenbergian variations of repeated materials within a completely normal binary formal structure. ${ }^{6}$ The opening repeated section (see the formal analysis on the following page) consists of two fourmeasure phrases leading to a cadence in measure eight and a short three-measure extension leading to a full close. The opening four measures trace a two-measure model and a repetition of a sentence-like thematic structure.

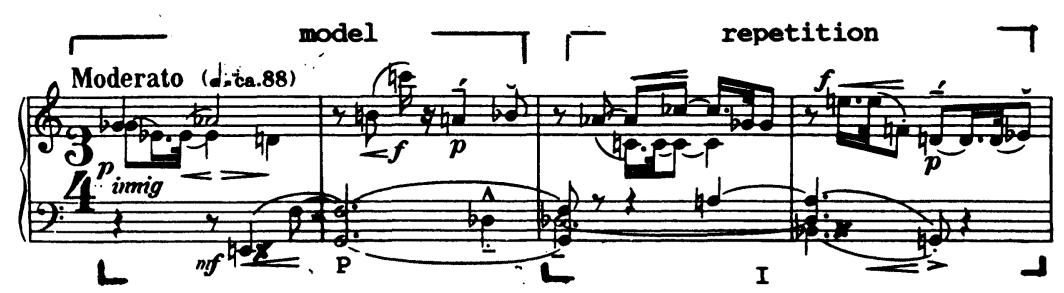

Figure 3. : Minuet from Suite Opus 25, measures 1 to 4

Figures 3 and 4 are used by permission of Belmont Music Publishers. Copyright 1925 by Universal Edition. Copyright renewed 1952 by Gertrude Schoenberg.

on F-natural which is strongly in conflict with the Neapolitan degree, F\#/G-flat.

6 For Schoenberg's conception of the form of the Minuet see Fundamentals of Musical Composition, Chapter 15, pp. 141-50. 
The second four measures present a sequence of "reductions" (they bear no real ressemblance to the initial model except perhaps for the very strong emphasis of the tritone) which are directed rhythmically, registrally, and dynamically toward the cadence in measure eight. The extension and closing cadence in measures nine to 11 can be seen as a necessary "spinning out" and balancing off of this dynamic and registral growth in the opening thematic structure.

As in the typical minuet form, a short developmental "bridge" ensues (measure 12-16), based upon the motives of the first two measures and leading directly to the varied return of the opening thematic structure in measures 17 to 25 . The return is extended in measure 23 by an interpolated cadence and a sequential repetition/extension which is added to the now transposed version of the original cadence in measures 25-26. (Note the inversion of all motivic ideas in the return of the opening material.) The original cadential extension emerges after a short and pointed sixteenth-note link (measure 28) and is even further closed by the ascending extension (measure 32-33).

Typical of Schoenberg's serial idiom, there is a strict correspondence of series statement and formal function. As seen in the example excerpted from Style and Idea below, the opening motivic model presents the series, but the treatment of the series in this piece is relatively free with many ordering changes (see Figure 4 in which the row indications are given on the score with an " $x$ " to indicate the first tone of the series). 


\section{Menuett}
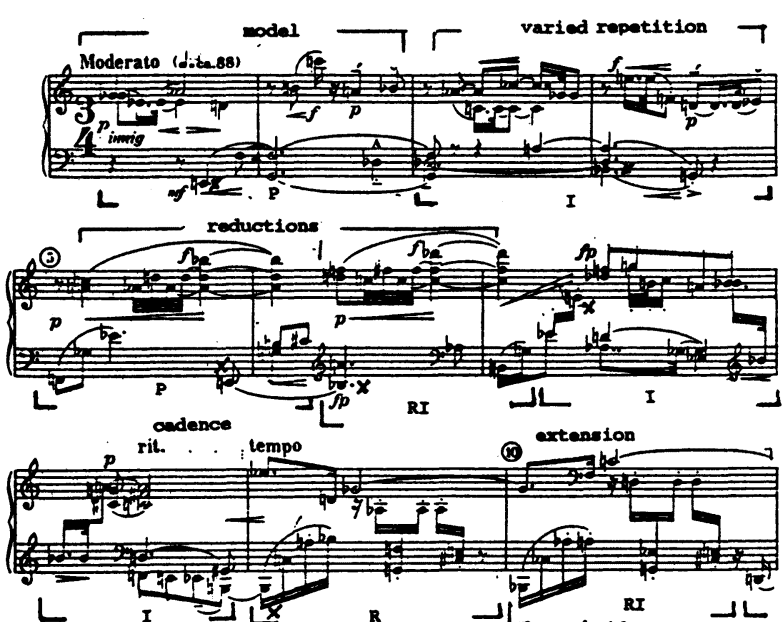

L

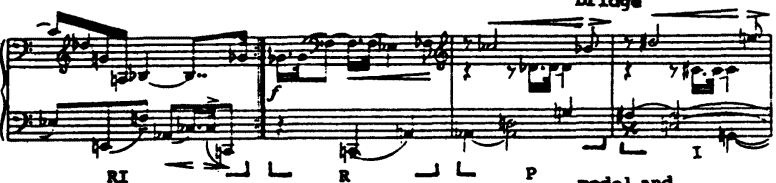

$$
\text { RI }=\text { L } L \text { R P nodal and }
$$
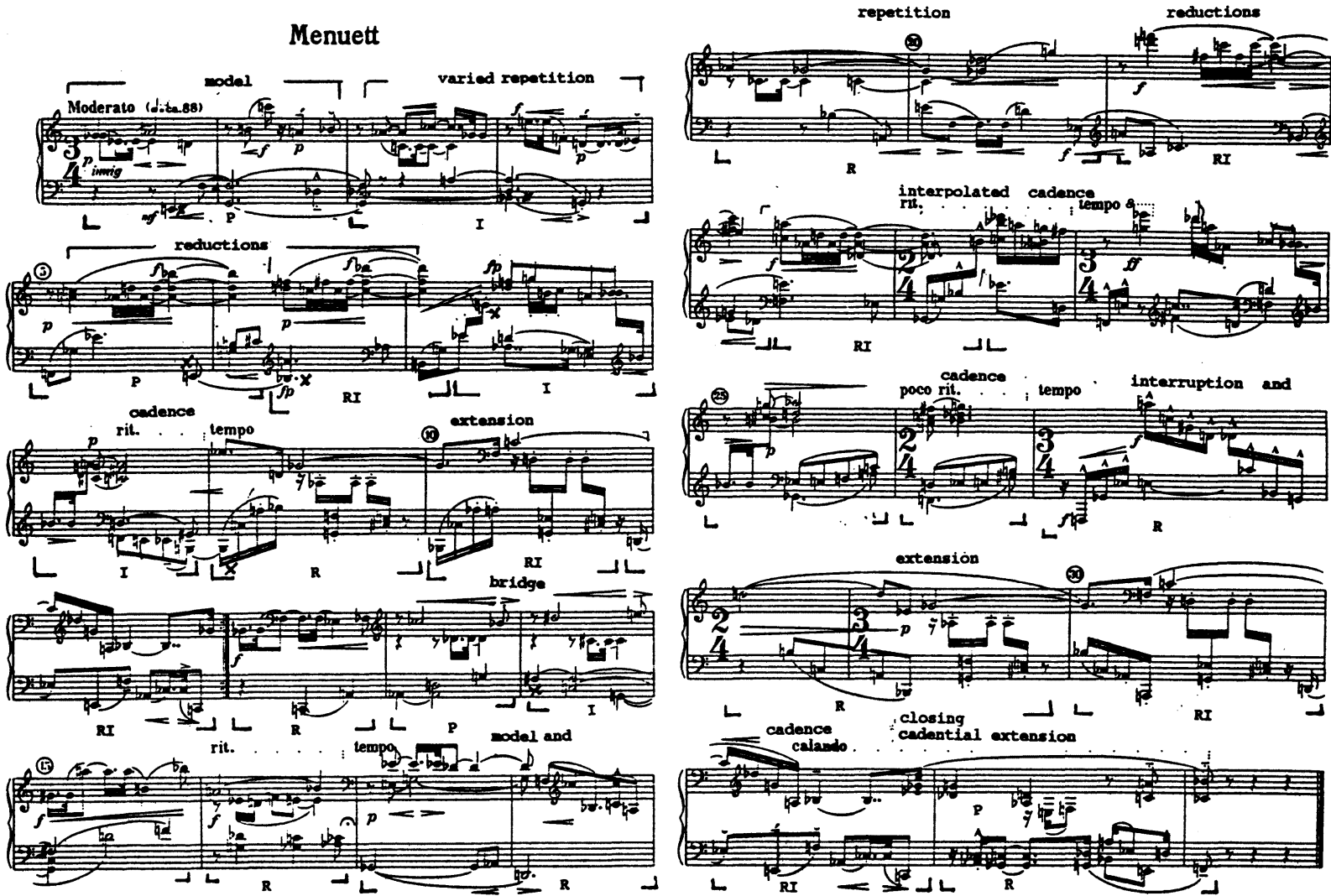

ᄂ

cadence calantial extension

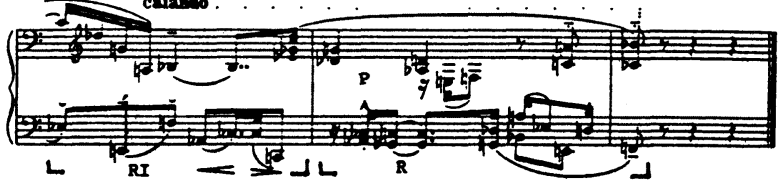

P R I RI indicate serial structurings withir parentheses $x$ indicates first tone of serial structure

Figure 4: Minuet from the Suite for Piano Solo, Op. 25 
As would be expected in a minuet, a clear logic of tonal centering is articulated within the formal structure. Looking strictly at the cadential tones of the upper melodic lines, it can be seen that the opening thematic model and repetition begins with the motion from E-flat to D and closes with the motion from $D$ back to E-flat (in the inner voice of the upper line of the texture). A secondary emphasis on B-flat is given in measure two which motivically and dynamically parallels that of the first melodic closure in measure four. The development portion of the theme (measures five and six) continues the E-flat emphasis now in the inner register which undergoes an octave transfer in measure seven. The cadence of measures eight and nine is clearly centered around B-flat, closing temporarily away from this tone on $\mathrm{A}$ before arriving with full emphasis on the lower B-flat at the end of the threemeasure extension. The overall motion from E-flat to B-flat is perhaps imitative of the opening period of the classical minuet which traces a modulation from tonic to dominant.

The bridge presents very direct emphasis on B-flat rising through two and a half octaves and closing with a lengthy appoggiatura in the midregister. It is interesting to see that the centerings on either B-flat or E-flat are not as clearly apparent in the return of the opening theme as they were at the beginning, perhaps as relief from the accumulation of emphasis on these principal tones.

Temporary emphases can be seen on $G$ in the melodic phrasings of the upper line of measures 25 and 26 . The dotted sixteenth-note/thirtysecond-note figure, however, intervenes again on B-flat but this time with the upward inflection to C-flat. As in the opening cadence of measure 11, the extension moves downward through the register to the emphatic cadence on B-flat and a further ascending extension produces the final B-flat as the goal of a chromatic linear motion.

An important secondary melodic emphasis in the piece can also be observed on G-flat which receives obvious formal weight in the opening motivic models, but also considerable attention at the cadence of measure eight (F-sharp in the inner voice) and in measure nine as the initial melodic emphasis of the cadential extension and as the opening tone of the bridge section. The closing phrase of the piece in its ascent 
to B-flat from G-flat further echoes the pivotal interplay of these two centers.

While the cadential logic of the Minuet seems quite clear, the full harmonic/contrapuntal sense of tonal function in this work is more complex and, at points, ambiguous with respect to traditional tonal interpretation. Essentially, however, the entire harmonic/voice-leading organization of this piece can be accommodated within two fundamental interpretive strategies. The first, which is entirely consonant with Schoenberg's earlier concepts of harmony, pursues triadic structure, roots and altered degrees, within the same restlessly modulatory framework exemplified in example 1 excerpted above from "Problems of Harmony". Examples of this type of harmonic organization can be found in the opening measures (measures two and three, specifically) where a strong root can be sensed on the G-natural of the bass as well as the ensuing root movements to F, E, G, and A-flat in measures five and six, as indicated on the harmonic reduction on the following page. ${ }^{7}$

A second interpretive strategy can be applied very successfully where a unified harmonic texture does not arise. As in certain sonorities in example 2 above it is possible to see very deliberate harmonic stratifications or superimpositions of different tonal functions. ${ }^{8}$ This

7 Note that, as in typical late nineteenth century harmonic textures, it is often difficult to find a single possible root for certain vertical structures. The opening measure, for example, can be viewed in terms of a sonority rooted on $F(D / f / A$-flat, with the $E$ as an appoggiatura) or on E-natural (E/A-flat[G-sharp]/D with the $F$ as a passing tone). This, however, is also an essential functional ambiguity of the late nineteenth-century chromatic language which Schoenberg's serial idiom was able to accommodate. Another particularly Schoenbergian predeliction which is indulged in the reductive analysis is that for unrestricted inversion of complex sonorities. This is indicated only where, because of only minimal chromatic alteration and minimal inversion, the harmonic identity and root can be perceived.

8 The reader is also urged to consult Schoenberg's analysis of an eleven-tone sonority from Erwartung in terms of stratified tonal components (See Theory of Harmony p. 418). Although this analysis is after the fact of the compo- 

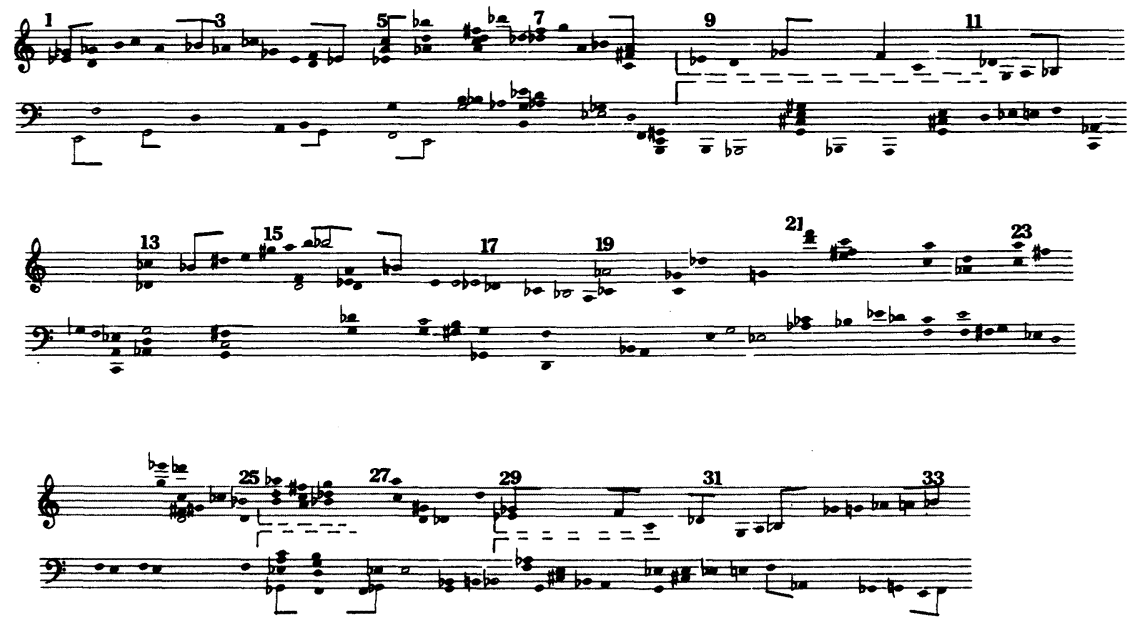

0 indicates root of harmonic sonority

$L===$ indicates tonally stratified texture

Figure 5: Analysis of the Minuet from the Suite Op. 25

sition, it must surely be indicative of Schoenberg's intuitive reasoning in his structuring of complex harmonic textures. 
is quite clear in measures nine to eleven where an upper melody in E-flat shifting to B-flat minor is set against a centering of a C-sharp/E-natural diad. A very important contrapuntal stratification can be seen at the cadence in measure eleven where the lower line of the texture is directed chromatically toward $\mathrm{F}$ against the upper voice cadence on B-flat. (This melodic stratification is repeated in measures 21 and 23.) Similarly at measure seven the upper line suggests quite clearly the chromatic tonality of B-flat minor against the very strong harmonic implications of E-flat minor in the lower voice. The notion of textural/tonal stratification is quite central to Schoenberg's musical language. His use of Haupt- and Nebenstimme indications are clear notational reflections of this and are as important tonally as they are texturally. Moreover, disparate tonal layers are very often suggested through contrasting dynamic superpositions as in the opening of the Minuet. ${ }^{9}$

\section{Conclusion}

The actual perception of the music as a unified harmonic texture or as a stratified contrapuntal texture is to a significant extent determined by the performer and his/her abilities to articulate such complex textures. Obviously, Schoenberg's idiom has posed substantial difficulties for traditional key-related harmonic and melodic interpretation. The acceptance of unrestricted chromatic alteration and inversion of triadic sonorities, and the extreme rhythmic density of modulation greatly obscures the necessary harmonic and melodic consistency upon which the perception of tonal function is based. In addition, this situation is anything but clarified in Schoenberg's thicker contrapuntal textures.

9 A third possibility of harmonic interpretation can be mentioned as a footnote here since it does not seem to be called for in the course of the Minuet. Certain complex vertical structures suggest neither single, key-related sonorities nor multiple harmonic stratifications, nor even alternate forms of harmonic coherence such as superimposed fourths or fifths. Passages dominated by such vertical organizations can be seen to neutralize triadic or key-related implications although the succession of sonorities may present centerings of certain melodic tones. 
The central goal of this discussion however, has been to recognize the particular consistencies of formal, melodic and harmonic organization which are articulated in Schoenberg's serial idiom. It is contended that there is more than enough substance to merit the leap of faith in the tonality of this music. Very important in this, however, are certain interpretive strategies by which tonal percepts can be maintained namely, the upper line melodic centerings (departures and returns, or directed motions to particular tones) and the interpretation of harmonic texture as a complex unified or stratified percept. The salient criticism arises that it is questionable to pose two different perceptual orientations to harmonic structure within the same work. In the Minuet, however, a very strong case can be made for the view that these two types of tonal organization function complementarily within the form of the piece. The opening of the thematic structure and bridge passage exert a strong harmonic definition which is diffused into the more tonally stratified contrapuntal percept at the cadences and extensions. Further research could define more clearly the relative formal roles of the vertically stratified versus the harmonically coherent textures in Schoenberg's serial works.

Ultimately, however, it must be recognized that accounts of the tonal form of individual serial works will have to make some recourse to the articulation of their serial structure which provides an underlying horizontal and vertical consistency beneath the coherent but less predictable tonal configurations of the surface structure. This is particularly true in Schoenberg's serial idiom which employs the typical repetitions of classical formal structure and in which there is such a close correspondence between formal and serial structure. ${ }^{10}$ It appears that at the heart of Schoenberg's serial music is the interplay between the underlying serial consistency (which is audible as a type of textural intervallic

10 This, however, would not be true of Webern's idiom where in addition to a very strong sense of cadence and tonal emphasis, there is more harmonic and vertical intervallic consistency (in the three or four-note intervallic cells) and obviously a much more transparent vertical texture. Moreover the actual serial structure itself is often obscured in Webern through elisions in the succession of row statements. 
background) and the particular surface manifestations of tonal logic and form. ${ }^{11}$ Every serial work, therefore, can be seen as a proposition of tonal and formal coherence under the unique premises of the individual series.

In conclusion, it is suggested that, rather than building our critical and analytical understanding of Schoenberg's serial music upon the compositional technicalities of the row, it is of far greater critical and analytical significance to relate perceivable tonal and formal structurings to the imposed contrainsts of the compositional method.

\section{REFERENCES}

Gerhard, Roberto.

1952: "Tonality in Twelve-Tone Music," The Score 6: 23-35, May.

Leibowitz, Rene.

n.d.: "A treatise on 12-tone composition," unpublished translation by Nancy François.

Ogdon, Wilbur Lee.

1955: "Series and Structure: an investigation into the Purpose of the Twelve-Tone Row in Selected works of Schoenberg, Webern, Krenek, and Leibowitz," Ph.D. dissertation, Indiana University.

Schoenberg , Arnold.

1967: Fundamentals of Musical Composition, New York: St. Martins Press.

1960: "The Orchestral Variations Op 31, A Radio Talk," The Score, 27 (July): 27-40.

1975: Style and Idea, edited by Leonard Stein. Los Angeles: University of California Press. [1950]

1954: Structural Functions of Harmony, New York: Norton.

1978: Theory of harmony, Berkeley: University of California Press. [1948]

11 See Roberto Gerhard (1952), p. 29. 